\title{
The Implementation Activist: How One Determined Person with a Camera Has Achieved Enforcement of Smoke-Free Laws throughout Thailand
}

\author{
Naowarut Charoenca ${ }^{1,2}$, Nipapun Kungskulniti ${ }^{1,2 *}$, Vasin Pipattanachat ${ }^{3}$, Siriwan \\ Pitayarangsarit $^{3,4}$, Stephen Hamann ${ }^{3}$, Jeremiah Mock ${ }^{5}$
}

\begin{abstract}
Background: Smoking and exposure to secondhand smoke are leading causes of disease and premature death in low- and middle-income countries (LMICs), where over $80 \%$ of smokers live. Over 152 LMICs, including Thailand, have passed laws designating that indoor and outdoor public spaces should be smoke-free. Throughout LMICs, implementation of laws has been a persistent problem. We identified one activist in Thailand who developed his own highly effective strategy for ensuring implementation of smoke-free laws, and whose approach has potential for being a model for implementation activists in other LMICs. Objectives: We set out to describe the implementation activist's strategy and impact, and to explore his perspective and motivations. Methods: We conducted in-depth interviews with the activist, reviewed video recordings and transcripts, and used narrative analysis to identify key themes and illuminating statements. Findings: In the implementation activist's assessment, administrators and officials were not being held accountable for their responsibilities to enforce laws, resulting in low public compliance. The activist developed his strategy to first identify public places where no-smoking signs were not posted and/or where people were smoking; take photographs of violations and make notes; and file citizen's complaints at police stations, submitting his photographs as evidence. The implementation activist documented over 5,100 violations of smoke-free laws throughout Thailand and reported violations to police. Often, police officers were unsure how to deal with his complaints, but when he educated them about the law, most undertook enforcement actions. The activist's work has contributed substantially to creating smoke-free schools, sports facilities and parks. Conclusion: This implementation activist's approach can be a model for preventing youth from using tobacco/nicotine, and preventing exposures to secondhand smoke and e-cigarette emissions. Based on his successes, we provide a list of elements that implementation activists can use to be effective, along with recommendations for policy and practice.
\end{abstract}

Keywords: Activism- implementation- smoke-free- laws- tobacco control- secondhand smoke- qualitative- Thailand

Asian Pac J Cancer Prev, 22, Progress of Tobacco Control in the South-East Asia Region Suppl, 19-34

\section{Introduction}

Nearly all low- and middle-income countries (LMICs) face challenges ensuring that tobacco control laws are strongly and consistently implemented locally, and that smokers universally comply with laws designed to create smoke-free public spaces (Open Society Institute, 2007; Minh et al., 2016; Wang et al., 2017; Byron et al., 2019). Such laws are passed to denormalize smoking and vaping and protect the public's health in public spaces like schools and parks. Yet, throughout LMICs, people often see in their everyday lives that the actual norm is that smoke-free laws are only "on paper," meaning that laws are not implemented or followed.
In this study, we describe the novel effective approach invented by one determined activist - Mr. Sanchai Tulabadi, known throughout Thailand as Loong Joon - to ensure that Thailand's smoke-free laws are implemented. Through his implementation activism, using his camera Loong Joon has dedicated much of his life to bringing about enforcement of and compliance with Thailand's laws designating smoke-free public spaces. In this report, we describe how this one activist effectively used Thailand's tobacco control laws and engaged Thailand's legal system to compel local officials in hundreds of communities throughout Thailand to fulfill their legal obligation and social responsibility to implement and enforce Thailand's smoke-free laws. The story of Loong

${ }^{1}$ Department of Sanitary Engineering, Faculty of Public Health, Mahidol University, Thailand. ${ }^{2}$ Center of Excellence on Environmental Health and Toxicology, Bangkok, Thailand. ${ }^{3}$ Tobacco Control Research and Knowledge Management Center, Thailand. ${ }^{4}$ International Health Policy Program, Thailand. ${ }^{5}$ Institute for Health \& Aging, Department of Social and Behavioral Sciences, University of California, USA.*For Correspondence: nipapun.kun@mahidol.ac.th 
Joon's creative grassroots efforts provides a roadmap for success while illustrating the importance of understanding how sociocultural context shapes an effective activists' perspective, and how sociocultural context influences how an individual activist goes about their work as a change agent.

Tobacco use harms and kills people disproportionately in LMICs. More than $80 \%$ of the world's smokers live in LMICs, and a similar percentage of nonsmokers in LMICs are likely exposed to harmful secondhand smoke (SHS) (The World Bank, 2020). There is no safe level of exposure to secondhand smoke indoors or outdoors (World Health Organization, 2000; US Department of Health and Human Services, 2006). Exposure to SHS remains a major concern because over 1 million deaths in LMICs every year are attributable to SHS exposure, accounting for $89 \%$ of all SHS-attributable deaths worldwide (Byron et al., 2019; Institute for Health Metrics and Evaluation, 2020; Yousuf et al., 2020).

Some LMICs have made progress over the past eighteen years in fulfilling their obligations under the World Health Organization Framework Convention on Tobacco Control (WHO FCTC) to pass laws to prevent youth from consuming tobacco and to protect nonsmokers from SHS exposure. Some LMICs have also moved to ban the sales and use of e-cigarettes to prevent use and protect the public from harmful exposures to toxic aerosol in secondhand e-cigarette emissions (SHEE) (ZavalaArciniega et al., 2018; Gravely et al., 2019).

In LMICs, relatively little research has been focused on identifying local success stories in achieving implementation of regulations where enforcement has been weak. In many LMICs, including Thailand, the sociocultural phenomenon of public acceptance of smoking, particularly in public spaces that by law should be smoke-free, has been a major challenge (Kyaing et al., 2011; Rashid et al., 2014). Overall enforcement has tended to be weak and compliance tended to be low, although conditions have been somewhat better in urban centers where resources were more easily mobilized (World Health Organization, 2011; Zhou et al., 2016). In many places, local officials who are legally responsible for implementing smoke-free laws such as school administrators, venue managers and police do not enforce smoke-free policies.

In our review of studies, along with two recently published reviews of the literature, we have found almost no mention of the important role local activists can play in ensuring that those who are responsible for enforcement fulfill their obligations under the law (Zhou et al., 2016; Byron et al., 2019). Scarcely any research has been conducted in LMICs looking at how local activists develop strategies that effectively ensure that those with enforcement responsibilities fulfill their legal obligations (Fong et al., 2015; World Health Organization, 2017; Byron et al., 2019). In undertaking this study, we have come to call people like Loong Joon who take up the cause of ensuring that laws are enforced and observed "implementation activists."

\section{Background}

In all societies, patterns of tobacco use and notions of law are shaped by the wider sociocultural context in which they occur (Unger et al., 2003; Kyaing et al., 2011). As the tobacco industry knows, sociocultural patterns can be major facilitators or major obstacles to implementation of and compliance with tobacco control laws (Nichter, 2003; Brandt, 2007; Hovell and Hughes, 2009; Irvin et al., 2015). Sociocultural context matters.

A recent review of the literature identified sociocultural patterns at the interpersonal and organizational levels that can be facilitators of compliance with bans on smoking in public places (Zhou et al., 2016). Group dynamics within a given sociocultural context in a specific setting have been shown to be strong correlates of smokers' compliance or noncompliance (Moore et al., 2009; Russette et al., 2014). Research has shown that smokers are more likely to support and comply with bans when total bans are in place and the restrictions are extensive, explicit and documented (Borland et al., 2006; Zhou et al., 2016). One study of sociocultural patterns at a college campus found that compliant smokers tended to report that if peers told them to not smoke in areas where smoking is prohibited, they would be less likely to do so, while noncompliant smokers said they would be more likely to follow the rules if citations were issued (Russette et al., 2014). Implementation studies have also shown that efforts to denormalize smoking in public settings can benefit from framing the reasons for enforcement as a "teachable moment" (Shopik et al., 2012). These research findings show that there are aspects of sociocultural context wherein implementation activists can focus their work.

In 2007, WHO issued guidelines for implementing Article 8 of the FCTC, stating that "effective legislation should impose legal responsibilities for compliance" and specify duties and penalties (World Health Organization, 2007a). WHO also said legislation "should identify the authority or authorities responsible for enforcement, and should include a system both for monitoring compliance and for prosecuting violators." WHO encouraged involvement of stakeholders and the public to ensure implementation, and recommended that monitoring could in most cases be integrated into existing inspection protocols at the local level that should be regular and unscheduled, and coordinated at the national level to ensure consistent enforcement nationwide.

WHO's guidelines stated that inspection visits should be made in response to complaints. Policies should be established "encouraging members of the community to monitor compliance and report violations greatly extends the reach of enforcement agencies and reduces the resources needed to achieve compliance... and smoke free legislation should specify that members of the public may initiate complaints and should authorize any person or nongovernmental organization to initiate action to compel compliance with measures regulating exposure to second-hand smoke." WHO noted that it is "essential that authorities be prepared to respond swiftly and decisively to any isolated instances of outright defiance." The same year WHO published policy recommendations for protecting the public from SHS exposure, including designating groups as inspectors such as public health inspectors 
who are backed up by other authorities (World Health Organization, 2007b).

In 2009, the Global Smokefree Partnership published Smokefree Air Law Enforcement: Lessons from the Field in which it described in detail how agencies could develop plans for effective enforcement (Bornhaeuser and Bloom, 2005). Within this framework, while most of the onus was placed on agencies to be responsible for implementation, the Partnership acknowledged the important role civil society groups could play advocating for strong enforcement, citing grassroots campaigns in Kazakstan videotaping violators and presenting information to journalists, and presenting their videos at local government hearings; trainings of health inspectors conducted by the Zambia Consumer Association; and work by the Coalition for Tobacco Control Pakistan conducting periodic observations to identify violations in public places in 10 regions, reporting to the Ministry of Health and WHO (Open Society Institute, 2007; Coalition for Tobacco Control Pakistan, 2008). The guidelines encouraged planners to build an official monitoring and enforcement infrastructure with mechanisms for members of the public to register complaints, but there were no lessons learned about how individual activists could go about substantiating their complaints. The researchers recommended that local governments should train inspectors to improve quality of inspections and mobilize communities, and that enforcement actions should be conducted according to the law, without perceptions of misconduct, corruption or tobacco industry meddling (Peruga et al., 2017).

These sources of guidance all recognized the role public health advocates working in civil society groups can play in pursing enforcement of policies, but the recommendations did not clearly discuss the vital roles individual implementation activists, as we call them, can play in ensuring enforcement. Little guidance was provided on how implementation activists could go about working effectively.

Only a few studies have identified successful approaches to achieving implementation in LMICs (Schoj et al., 2010a; Schoj et al., 2010b; Thrasher et al., 2010; Campelo, 2011; Crosbie et al., 2011; Gvinianidze et al., 2012; Li et al., 2013; Thrasher et al., 2013; Ye et al., 2015; Nemakhavhani and Akinsola, 2016). Among these studies, still fewer have discussed how implementation activists can play a crucial watchdog role to ensure that laws are enforced and observed (Open Society Institute, 2007; Crosbie et al., 2011).

In LMICs, the nonsmoking public's dislike of smoking has been identified as the greatest facilitator of enforcement of and compliance with tobacco control laws designating smoke-free public spaces (Janghorbani et al., 2004; Chang et al., 2009; Owusu-Dabo et al., 2011; Vardavas et al., 2011; Radwan et al., 2012). A major study in China showed that $90 \%$ of the public support smokefree indoor environments (World Health Organization, 2019b). In some cases, public pressure can strengthen the will of legislators and local government officials to create conditions that will promote healthier lives for young people and protect communities from exposure to tobacco toxins (Barnsley et al., 2017). For example, partnerships between local governments and civil society groups, like those in India, have been shown to produce public declarations of smoke-free communities (Kashiwabara et al., 2011; Kaur and Jain, 2011). The challenge often comes from not seeing those public declarations implemented.

Some of the most common causes of weak implementation of tobacco control laws are lack of will on the part of government officials and the police to enforce laws (Staff reporter, 2018), and the lack of financial and human resources dedicated to enforcement (Open Society Institute, 2007; Panda et al., 2012; Turner et al., 2016). In LMICs, typically the number of enforcement inspections made each year to ensure compliance is limited. In 2011, WHO estimated that the adoption and enforcement of a national comprehensive smoke-free law would have a per capita cost of US\$1.60 (Chisholm et al., 2011). Other estimates for Southeast Asia are much lower at about US\$0.25 (Muller, 2008). Legislation and enforcement have been successful in some countries such as Brazil and Colombia where substantial resources were dedicated to changing norms about smoking in public places (Mendes et al., 2017; Uang et al., 2018). Still, these countries also encountered many of the same challenges faced by other LMICs. For example, in LMICs, it is common for school administrators to not be empowered to enforce smokefree laws within and near their school grounds (Zhou et al., 2016).

Another aspect of the problem is dealing with lack of public awareness. In many LMICs, public awareness about the dangers of secondhand smoke has been found to be low resulting in lower levels of compliance (Ahuja et al., 2018; Dang et al., 2018; Nyi Latt et al., 2018; Robertson et al., 2018). A related problem is the lack of no-smoking and other educational signage. Often, required signage is not posted because those responsible have not received or made efforts to obtain signage, or if signage has been posted, it becomes damaged, faded or degraded.

Where these wide gaps exist, sometimes NGOs and coalitions intercede to address the problems. In some communities facing tobacco industry infiltration, coalitions have been able to bring together decisionmakers, key stakeholders, and community members to work as change agents on the implementation of tobaccofree policies (Douglas et al., 2015; Irvin et al., 2019). In some cases, NGOs and coalitions are able to appeal to "champions" who are influential in the political arena (Montini and Bero, 2008; Barnsley et al., 2017). Some NGOS have been able to take strong legal stands in their own communities and received recognition for their work. For example, the Burning Brain Society (BBS), Chandigarh, India, discovered that Godfrey Phillips India Ltd. (GPI) was deploying young product promoters under the guise of being "researchers" to push a youth-oriented brand inside of one of India's most prestigious universities (Goswami, 2006). This promotion was in violation of India's law banning tobacco product sales within 100 yards $(91.4 \mathrm{~m})$ of all educational institutions. When members of BBS discovered GPI's illegal activities, they reported them to the police and government agencies. After no enforcement action was taken, BBS went to the press to 
increase pressure. GPI threatened to sue for libel. Facing continued police inaction, BBS took their own initiative to physically detain one of the promoters, thereby forcing the police to confiscate the advertising materials and file a complaint against GPI. For this and other BBS legal action to promote the implementation of FCTC Article 8 in Chandigarh, India, Mr. Goswami, the leader of BBS, received an award for his community work from the Global Smokefree Partnership in 2008 (American Cancer Society, 2008).

One of the few in-depth studies to examine the role activists have played in tobacco control enforcement focused on activists' roles in ensuring that California's newly passed law banning smoking in bars was implemented (Montini and Bero, 2008). This study highlighted the essential that even after legislation went into effect, enforcement was delayed, and many locales failed to do anything to implement the law, resulting in low compliance. The study showed that under these circumstances, activists intervened and addressed breakdowns in implementation by notifying local authorities that they were considering filing a writ of mandamus notifying the court that a law exists that authorities are refusing to enforce. The activists played important roles in recognizing where there was a lack of coordination between local agencies like police departments and offices of city attorneys. They recognized the causes for the gaps in enforcement because they could see "the big picture" from their overarching perspective. They recognized when they needed a "champion" to wield influence, and when to focus pressure on an agency or official that was the "weak link."

In Thailand, a middle-income country that has been widely recognized for its tobacco control achievements, implementation and compliance with laws that prohibit youth tobacco consumption and ban smoking in public areas have been somewhat successful in urban centers where civil society groups have been active (World Health Organization, 2019c). Nevertheless, implementation has often been lacking and compliance has been uneven throughout much of Thailand (Kungskulniti et al., 2018; World Health Organization, 2019c). In Thailand, two expert assessments and a stakeholder analysis of smoke-free provisions of FCTC Article 8 showed limitations of enforcement provisions because of a lack of engagement with the general public to bring pressure to bear on responsible parties to implement smoke-free laws (Southeast Asia Tobacco Control Alliance, 2016; Peruga et al., 2017; Kungskulniti et al., 2018). One of the biggest problems tobacco control activists face in Thailand and in other LMICs when working on implementation is getting access to information about effective strategies from other activists working on environmental prevention and implementation.

Prevalence of youth smoking and exposure to SHS in LMICs and Thailand

Despite the passage of tobacco control legislation in many countries, youth smoking remains a serious problem. An aggregated analysis of school-based surveys on youth smoking conducted from 2006-13 in 68 LMICs, showed that the prevalence of smoking by youth ages $12-15$ years old ranged from 2.8 to $44.7 \%$ (mean $13.6 \%$ ) (Xi et al., 2016). In 2015, the prevalence of smoking among Thai male youth ages $13-15$ was $21.8 \%$ and among female youth $8.1 \%$. Because Thai law prohibits sales of e-cigarettes and heated tobacco products, little is known about the prevalence of youth use of e-cigarettes and heated tobacco. However, in $20153.3 \%$ of Thai youth reported using electronic cigarettes (Chotbenjamaporn et al., 2017).

Aggregated analysis of data from 68 LMICs showed that the prevalence of youth exposure to SHS ranged from $16.4 \%$ to $85.4 \%$ (mean $55.9 \%$ ). In Thailand, the prevalence was $40.0 \%$. In the 68 LMICs, SHS exposure was a risk factor for young adolescents initiating tobacco use (OR=2.56, CI, 2.43-2.69) (Xi et al., 2016).

\section{National-level activism and passage of tobacco control laws in Thailand}

In Thailand, tobacco control advocates and activists have made substantial impacts in the policy arena. In response to transnational tobacco companies forcing their way into Asian countries with their products in the late 1980s, Thailand took a strong stand against them. Although eventually Thailand was forced to open its market to foreign tobacco products in 1990, the more than two year opposition of both government and civil society leaders resulted in a new and sustained activist movement against tobacco interests and for tobacco control.

Thailand was an early leader in establishing strong tobacco control laws, and has expanded designations of smoke-free areas (Vateesatokit et al., 2000). In the beginning there were only a few champions working at the national level on tobacco control. A movement grew through the activism of diverse stakeholders and supporters in communities throughout Thailand. In 1992, Thailand's government passed the Tobacco Products Control Act and the Nonsmokers' Health Protection Act, the first major legislation designed to reduce smoking and prevent SHS exposure by banning smoking in public places (Royal Thai Government, 1992a; Royal Thai Government, 1992b; Tobacco Control Laws, 2020).

In 2000, the government defined detailed regulations for implementation and enforcement of a few designated smoke-free areas, including government buildings and schools (Royal Thai Government, 2010). After 2000, regulations were gradually updated to establish comprehensive smoke-free coverage of more than 40 indoor and outdoor public spaces. Tobacco control activism led to the establishment of an alcohol and tobacco tax-based health promotion organization, the Thai Health Promotion Foundation (ThaiHealth) in 2000 (Siwaraksa, 2003). ThaiHealth allocates revenue from excise taxes on tobacco and alcohol to fund major programs addressing tobacco and alcohol use and non-communicable diseaseprevention programs like reducing traffic injuries and improving nutrition and exercise.

In 2005, Thailand became a party to the WHO 
FCTC and moved rapidly to pass five notifications to the smoke-free law to bring Thailand into compliance with its obligations under the FCTC (Wissarutwong, 2009). Member countries were obligated by the treaty to establish $100 \%$ smoke-free places within five years. Thailand concentrated on passing further notifications of the Nonsmokers' Health Protection Act to ensure it could meet the requirements for coverage and implementation of Article 8 of the FCTC, 'Protection from exposure to tobacco smoke.' The same year, the Thai Health Professional Alliance Against Tobacco, a network of 20 medical professional organizations, was founded (Thai Health Promotion Foundation, 2011). That year Loong Joon began filing his work as a local implementation activist.

In 2008, Thailand launched the Toward $100 \%$ Smoke-Free Thailand program, which continued to 2011 in an effort to bring greater public compliance with bans that covered new locations such as pubs and bars and entertainment venues (Kungskulniti et al., 2018). By 2010, WHO recognized Thailand as having passed laws and developed regulations to make public places $100 \%$ smoke-free because smoking was prohibited in all indoor public places, indoor workplaces, public transportation, markets, and in outdoor areas including facilities for recreation, exercise, sports training, sports competitions, and in all public parks including national parks, municipal parks, zoological parks, amusement parks, and children's playgrounds. Throughout these years, Loong Joon continued to work to personally see that these laws were implemented locally.

In 2017, the year after Loong Joon retired from his work as a local public health officer and dedicated almost all of his time to being an implementation activist, Thailand substantially revised its national tobacco control laws passing the 2017 Tobacco Products Control Act, including prohibitions on the sales of e-cigarettes and heated tobacco products (Royal Thai Government, 2017; Tobacco Control Laws, 2020). The list of locations where smoking is banned was expanded, and some administrative provisions were upgraded. However, the latest WHO Report of the Global Tobacco Epidemic, 2019 rated Thailand only five of ten for compliance with Article 8 since there are substantial weaknesses in implementation in some locations (World Health Organization, 2019c). From 2016 through 2021, Loong Joon continued to be active working to see that smoke-free laws were being implemented locally.

\section{Materials and Methods}

Loong Joon's work came to our attention from respected tobacco control activists like Drs. Hatai Chitanondh and Prakit Vathesatogkit who recognized Loong Joon's personal initiative to ensure that government authorities and officials were fulfilling their responsibility to enforce Thailand's smoke-free law at the local level. Several newspapers had also highlighted Loong Joon's efforts. Based on this information, we investigated what Loong Joon had been doing. We contacted Loong Joon about our research interests and he enthusiastically consented to participate.

Our objectives were to examine the background, circumstances, perspective and motivations of Loong Joon to understand how he developed his strategy and to learn from his own perceptions of the impact of his work. We developed a research protocol to understand his motivations and reasons for doing his work as an implementation activist. We read and analyzed newspaper articles about Loong Joon. Then, we set out to learn about his background, document and analyze his procedures for dealing with violations of Thailand's smoke-free law, explore his self-assessment of his successes and failures, and obtain his recommendations for achieving greater compliance with the law. We conducted a series of indepth, semi-structured interviews with Loong Joon over several days which were recorded on digital video. Before the interview, we developed an interview guide with an iterative series of qualitative questions. To give Loong Joon the opportunity to prepare himself, we sent questions to him several weeks before the interview. After the initial video interview, we conducted a preliminary assessment of what we had learned, and we contacted Loong Joon again by telephone to ask him some follow-up questions.

We transcribed and translated the interview content into English. We conducted content analysis of the Thai video data and the English transcripts to document specific information about Loong Joon's professional experiences. We asked for his perceptions about the enforcement and compliance context, his development of his strategy, and asked him to identify the successes and implications of his efforts as he viewed them. Since this study sought to benefit others through Loong Joon's experiences, we focused primarily on summarizing the main points and the identification of themes in the interview. We followed up with Loong Joon to ask him about his progress. The findings we present here are based on our content analysis confirmed by Loong Joon. The research protocol was approved by the Tobacco Control Research and Knowledge Management Center.

Through narrative analysis, we examined how Loong Joon developed his unique perspective as a highly motivated implementation activist. Based on our analysis, we sought to uncover distinctive aspects of his upbringing and early adulthood that shaped his motivations and his professional trajectory. We examined his assessment of the problems of weak enforcement and low compliance, details about the approach he developed, reactions to his efforts, and the risks he has taken to achieve compliance. We distilled insights about his underlying motive, his assessment of his impact, and his advice to others. Based on our understanding of problems in LMICs in achieving enforcement of and compliance with smoke-free laws designed to prevent youth tobacco consumption and protect nonsmokers from SHS exposure, we evaluated whether Loong Joon's novel and effective strategy had the potential to be a model for activists working in other LMICs who wish to achieve smoke-free goals.

\section{Findings}

Loong Joon's assessment of the problem

Since the beginning of his career three decades ago as a

Asian Pacific Journal of Cancer Prevention, Vol 22 
local public health officer, Loong [uncle] Joon worked as a public health legal specialist in the provincial health office. Loong Joon believed laws were important and that officials should be held accountable for publicizing and enforcing laws. In his province he had tried to educate and pressure school directors, mayors and the governor to issue official notifications to officials requiring them to post permanent signs in schools, markets, public parks, and sport facilities, and to enforce the law. After these efforts, he observed continued low compliance with national tobacco control laws. In Mukdahan and throughout Thailand, Loong Joon observed that at almost all public locations there was no compliance with the law. At almost all public locations, signs were not posted stating that the area was designated nonsmoking. He observed that nearly all smokers in general, including heads of organizations did not comply with the law. Based on his observations, he reasoned that the lack of compliance was caused to a large degree by a general lack of enforcement which occurred because there was no accountability.

"There is no compliance with the law [by administrators and Buddhist monks]. Article 5 of the law states that 'no-smoking' signs must be clearly posted at the entrances of public places. It is their duty. After educational meetings, I had expectations that they would abide by the law, but they did not...People do not comply with the law because authorities avoid monitoring."

"I would like to see more effective enforcement. Higher administrators do not give importance and seriousness to enforcement, leading to weak actions on this issue. By law, the authorities are not punished when they do not take action for enforcement. Public places like schools, markets, public parks, and sport fields should be monitored and enforced routinely."

"Smoking in transportation terminals produces serious impacts on travellers each day. The posted 'Nosmoking' sign no longer affects those smokers. They get used to ignoring the sign since no enforcement is done. People in Mukdahan were disappointed when there was no enforcement by local authorities. I would like the officers to enforce the law more strictly. Fining must be implemented, rather than just warning. Warning has no effect."

Loong Joon thought the root cause of widespread lack of enforcement was that public health personnel did not seek the cooperation of local law enforcement officials because public health personnel were fearful of provoking negative reactions from noncompliant administrators of government services and religious orders who were responsible for implementing national tobacco control law at the local level. He felt that public health personnel feared working with police to confront those in positions of responsibility. Thus, officials in almost every subdistrict who were responsible for enforcement did not take responsibility to perform their duty to inform the people. Rather, they ignored their duties. They did not monitor the locations in their jurisdictions. From his comments, it appeared that the main reason the local officials ignored their responsibilities enforcing the law was because they did not take the issue of smoking seriously, possibly because many of them were smokers. He noted that many local officials also wanted to avoid what they felt was unnecessary confrontation.

\section{Loong Joon's approach}

Loong Joon's observed that teachers and Buddhist monks at temples, people with responsibility for teaching values and good habits to the next generation, tended to not comply with the national no smoking law. This caused him to see that working toward enforcement of Thailand's national laws prohibiting smoking in schools and temples and requiring no smoking signage presented an opportunity to reshape attitudes in critical locations. Because of his many years working as a government health official focused on legal affairs, he understood how the legal system worked, and he had self-confidence about using the government system and dealing with the police.

After Loong Joon retired in 2016 he became a full-time tobacco control activist. He developed a unique strategy to use the legal system to achieve his goals. He developed a procedure to first identify public places such as schools, temples, businesses and government offices where no-smoking signs had not been posted and/or where he observed smokers smoking. Then, he would take photographs of these violations to generate evidence and make notes, primarily about a lack of signage in required areas and/or smoking in areas where smoking was prohibited. Next, using his photographs and notes, he would file a citizen's complaint at the local police station about specific violations of the law, submitting his photographs as evidence.

"After my retirement, I had time to go to many provinces throughout the country. Working in the legal section of the provincial health office for so long, I knew how the system works. For effective enforcement, a complaint, with a good evidence, of a violation must be submitted to the police so that they can process further. So, when I find violations in public places/offices, I take pictures, which takes 1-2 minutes. I do not take time talking to anyone because nobody knows me, I am just an individual doing it for my own purpose. I can document many violations at different places in one day. Then, for each case, I prepare a written complaint with an attached photo and my ID to send to the police chief of the province."

To prevent avoidable negative impacts on officials, before filing his complaints, Loong Joon held meetings in schools and with higher-level officials. He did this to give those who were responsible for enforcement fair warning and an opportunity to address the problems he identified. In most cases, those who were responsible politely ignored him. When that happened, he engaged in his procedure of observing, taking photos and filing a citizen's complaint. In presenting evidence of violations to the police, he used the law to apply legal pressure to persons of responsibility to require them to uphold their duties and enforce the law.

\section{Reactions from police and government officials}

As Loong Joon has gone from province to province and from town to town throughout Thailand using his procedure, he has found that local police are initially somewhat mystified about why he is filing complaints, 
and confused about what he expected them to do. Once he has documented a violation and reported it to the police, the problem then shifts to ensuring that the police follow through with enforcement action. Loong Joon has had to educate local police about tobacco control laws and encourage them to enforce the laws. In general, once he explains the law to the police, he receives their support. The police generally follow through on his complaints by conducting their own investigations, and when they determine there has been a violation, they warn those responsible and in some cases issue citations.

"When I reported to the police, initially they did not understand because they did not know about the tobacco control law. They were surprised because nobody had reported or filed a complained like that before. So, it depended on the police themselves. Some police paid attention... I complained to the Nakhorn Pathom provincial and district police, and it was good. They fined the violators. When I went to other provinces, for the first two years the police did not respond because they did not think it was their job. But then later the police paid more attention."

"At first, police did not understand because they had not received any complaints, and they did not know about the tobacco control law. Later on, the police responded better. For example, in Hatyai district, I sent complaints to the police with photos I had taken in one day of seventy schools, temples, and mosques where there were no signs at the entrances. And, I got a good response from the police. I took action without contacting any persons at those places. In order to get enforcement of the law, a complaint must be filed by someone."

In most towns, local police eventually undertake enforcement actions including issuing citations, and most local officials comply. In a few cases, Loong Joon's complaints have been met with bold resistance. For Loong Joon, one particularly important case was when the public health officer in his own province where he had worked for three decades decided to be uncooperative and circumvent the law. However, this level of resistance has been unusual, and was not followed by others.

"In Mukdahan in 2014, I received a protest by twenty people about people selling locally grown shredded tobacco for hand rolling that had no health warnings on the packaging, and about a school director who had not posted a sign at the school entrance. However, [when the police issued a citation] the Mukdahan public health officer agreed to pay the fine for both cases. The public health officer forced me to withdraw my complaints. Following these incidents, the school director threatened that he would not cooperate with the public health office for any activities in the future. When the Mukdahan public health officer paid the fine for the violators, other schools began to ask for help [to pay their fines]."

"In other provinces, there were no more protests. Nobody dared to ask public health officers to pay the fine. Instead, I received phone calls [from officials who had been cited] to thank me. Some even sent pictures of themselves complying with the law. The school directors paid the fine even though they knew that I filed the complaint."
Through this experiences, Loong Joon has realized that he could not assume that public health officers would automatically be supportive of his work. He has made more efforts to lay the groundwork with local public health offices before initiating his complaints to ensure that enforcement action would be successful. He has often been surprised that once violators were cited, some have showed appreciation for his efforts to bring the importance of enforcing the law to their attention.

\section{Loong Joon's overall self-assessment of his impact}

Loong Joon has been quite modest in characterizing his impact, given the depth and reach of his work. Over the past three decades, Loong Joon has worked successfully as an implementation activist to ensure enforcement of Thailand's smoke-free laws and policies primarily in schools, hospitals, community clinics, and other government buildings. Since 2005, Loong Joon has filed over 5,100 citizen's complaints at local police stations reporting lack of enforcement of smoke-free laws and lack of required signage in public areas. In his home province of Mukdahan he filed 450 citizen's complaints, and the police followed up on all of them. In Bangkok and the other seventy-five provinces in Thailand where he undertook his activism, between 2008-18 he filed 4,172 citizen's complaints, educating the police about their responsibilities to enforce Thailand's tobacco control laws, and about $25 \%$ of his complaints were followed up by local police. Over the past two years, because he has become better known nationwide, local police have followed up on about $45 \%$ of his complaints.

As an implementation activist, Loong Joon has decided to continue doing what he feels would be most effective on his own personal time. He has found that his activism has produced measurable impacts, even if local responses to his efforts have not been uniformly effective. In the four years after he retired, he has traveled to all of Thailand's seventy seven provinces at his own expense, and he has implemented his procedure in cities, as well as in large and small towns.

"My intention was to see enforcement implemented in all provinces, but this still cannot be fully achieved...I have reported violations to the police and there are positive responses in all provinces. My advice was accepted and implemented by local organizations and temples".

Through his experiences, he has found that it is difficult, but not impossible, to change local culture and the attitudes of some public officials. He has come to realize that the difficulty in achieving changes is influenced by the Thai cultural context in which many Thais are reticent to criticize other's work or make others feel put upon. Still, given that nonsmokers express concerns to him about lack of enforcement and compliance, and officials have expressed their thanks for his efforts, he has persisted with dedication working at the local level to pressure officials to enforce existing laws.

\section{Professional and personal risks of filing complaints}

Over three decades of working in his region's public health department on tobacco and alcohol control, Loong Joon developed a strong reputation throughout his region, 
and he was generally respected for his efforts by the general public and officials. In particular, he was respected for standing up against powerful alcohol companies. He has been able to work freely without fearing intimidation from the tobacco industry or being impeded by tobacco industry meddling.

As a consequence of being a bold and sometimes outspoken official, near the end of his career in government service, he was reassigned off of doing tobacco control work because his supervisor did not agree with his strict approach to policy enforcement. So effectively he was sidelined near his mandatory age of retirement.

"The biggest disappointment was that I was forced to stop working for six months in tobacco/alcohol control two years prior to my retirement. However, during that time I continued reporting on violations on the weekends and outside of office hours. I was encouraged by colleagues to continue my work since it is the right thing to do."

Generally, Loong Joon's work has gone unchallenged by local people. However, occasionally he has experienced threats and some actual damage to his motorcycle. Throughout Loong Joon's professional career and retirement, he has been single. So, he has not had to be concerned about people threatening or harassing family members, something that others might be concerned about.

"They [public health workers] think it is a risk of being disliked by the people. It is different from province to province."

Loong Joon realizes there are some risks associated with the work he does, but he has decided to keep going with his work. He has conducted observations and taken photographs discretely, often on the weekends, so he was able to avoid being identified and therefore avoid criticism. In the end, he is an activist who since his days as a student demonstrator has become accustomed to taking some risks for his principles.

\section{Additional strategies}

In addition to his main strategy working at the local level, Loong Joon also worked to put pressure "upstream" at high levels of government so that pressure would come back "downstream" to require accountability at the local level. For example, in 2017, Loong Joon traveled to different regions of Thailand. In Petchaboon province, he found more than 100 cigarette butts on the sidewalk near the entrance of a district hospital. He visited Krabi Provincial Hospital and found about 200 cigarette butts in 24 locations. At the entrance of a shop, he found a sign advertising a cigarette brand with a price (which is illegal in Thailand). So, he decided to write a letter to the Director General of the National Disease Control Department reporting his findings.

Loong Joon also submitted a letter to the Director General with his suggestions of addition that he felt should be included in proposed legislation that became the 2017 Tobacco Products Control Act, including banning the sales of tobacco products within the boundary of government offices and public enterprise offices, at festival activities, in transportation terminals, and at open markets. He recommended that stronger enforcement should be implemented at places for banning smoking such as hotel rooms, apartments, dormitories, government buildings, places selling foods and drinks, and gas stations. His recommendations were considered in a meet of the legal section of the Bureau of Tobacco Control at the National Disease Control Department. Source of motivations

In the early 1980s, Loong Joon became committed to working locally and his primary focus was to create a new generation of youth who were 100\% smoke-free. He focused on preventing young people from taking up smoking, and helping smokers quit. He also became very committed to protecting nonsmokers from secondhand smoke exposure. Loong Joon's work on youth prevention and cessation coincided with emerging efforts to reduce the national smoking rates among male adolescents.

"I am interested in educational institutions because I do not want youth to start smoking and become addicted to smoking. My concern is that when they grow up, they will be just like their parents because we are still dealing with high smoking rates among adults. We don't want Thai society to experience an increase in smoking rates. So, I think the right place to stop it from increasing is at educational institutions. Those who have not started smoking yet, I don't want to see them do that in the future. So when looking at the law, I was thinking the education institutions should be the place to start working."

When Loong Joon looked at the various places where smoking was prohibited by the new Nonsmokers Health Protection Act passed in 1992, he identified elementary, middle, and high schools as places where he should focus his work because he felt that schools were where young people learned about things in everyday life like smoking.

\section{Foundational experiences}

Loong Joon became interested in tobacco control as an extension of what he learned when he was a college student participating in the political meetings with students and the massive student demonstrations at Thammasat University in Bangkok. The student movement for social justice was grounded in the political science department. The main topics he was interested in were examining the root causes of inequality among Thai people and the drivers of social injustice. Like many student activists of that era, he took up the commitment to improving the lives of poor people, particularly in the countryside, saying, "During my college years, I devoted myself to rural and community health."

After graduating in 1976, Loong Joon started his professional life as a public health official in one of Thailand's remotest provinces - Mukdahan. Loong Joon went out to work with the people in rural areas to learn about their lifestyle in the villages and he stayed with them and worked with the farmers there. He started his pioneering tobacco control work developing a cessation model and then shifted into advocacy work.

"From 1988-2008, my main responsibility was in tobacco control. I started a cessation clinic in Mukdahan. It was so successful that the Ministry of Public Health used it as a cessation model. Since then, as a tobacco control advocate, I have been invited to give speeches in many provinces. In 2008, I was assigned to be responsible for alcohol control, and I was very well-known as a strict 
officer in that work."

\section{Underlying motive}

Loong Joon's main motivation is to improve society without seeking personal recognition. He has sought to improve society by preventing and reducing smoking, and by ensuring that the rule of law is respected and enforced. His motivation is grounded in the moral teachings of selflessness he was exposed to in the Catholic school and the Buddhist monastery where he studied. His desire to improve society is rooted in his experience as a student activist when he learned about social injustice in Thailand. During that time, like many students he resolved to work especially hard to improve the lives of the rural poor. He decided that for the Thai public, good health is more important than anything else, and that the laws should be justly enforced and complied with without regard to one's social status or position. He decided that government agencies were not effectively protecting the public's health mainly because public health officials were constrained by bureaucratic procedures. So, he decided to work independently and use the levers of the law to instigate change. In some cases, to apply pressure and educate the public, he contacted local newspaper reporters to alert them of the violations, and that the police would probably be issuing a citation.

"Other officers are working in the red tape framework, but I am not. My ultimate goal is working for the good health of people. I have worked alone and outside office hours in doing enforcement. Enforcements are conditional upon social status of those who violate the law. If the general public is treated differently from those who have influence in society, who will trust the officers anymore?"

"I think nobody would dare to repeat as I have done. But I hope I can stimulate people to be more aware about better law enforcement. Public health officers at all levels should be aware of their responsibility regarding law enforcement. Another example is in Nan Province where no temples posted no-smoking signs. I was asked why I did not tell the abbot at the temple to post the sign. If I told the abbot, he would just be silent. So, it is better to report to the police and newspaper reporters. This way, the whole society will know of the law."

Loong Joon has been on a mission to raise public awareness about the importance of preventing youth smoking and eliminating exposure to secondhand smoke in his region and throughout rural Thailand. Preventing smoking among youth, helping smokers quit, and protecting the public from secondhand smoke exposure have become his personal cause, and he has deliberately decided to focus on working in underserved provinces. He plans to work on this for the rest of his life as long as he can manage it. Loong Joon's advice and recommendations to achieve widespread implementation

In Loong Joon's view, local public health officials should be given more authority to enforce laws. Moreover, the national and provincial governments should hold officials who do not enforce the laws to account, including through administrative punishment. He believes that the national government and local jurisdictions should set real measurable goals, and that more resources should be invested to support research to measure whether the goals are being achieved.

"Public health officers should work cooperatively and routinely with police to arrest the violators. I suggest that local public health officers should have more authority like the Thai FDA."

"The current law does not have any statement about achieving measurable goals. Local enforcement is weak. Local public health officers emphasize campaign contests, which have little effect on society. This is superficial, meaning that they focus on contests, but I believe in results."

"I recommend that there should be punishment for local officials who do not take action. The Ministry of Public Health does not give importance to proactive prevention measures. There should be a clear goal indicating how many, what percent of smoke-free public places were achieved each year."

He has believed that research on local conditions is important because it would provide further evidence to cite as part of public efforts. It has been difficult for him to attract academic researchers to study tobacco control problems in rural communities.

Loong Joon recommends that anyone who wants to have an impact should do their own fieldwork (research) and document what is happening with photographs and notes. This has been an efficient way for him to gather information. These tools have been powerful for him in producing irrefutable evidence that he was able to submit in his citizen complaints to achieve enforcement.

"People can be volunteers by taking pictures of any violations, then report directly to governors, so that these complaints will be discussed for solution in local administrators' meetings."

"I can train others with some conditions. I am not very skillful in teaching the new generation, but I can share my experience with them and offer myself as an example."

Loong Joon thinks that holding officials accountable is critical. At the same time, he thinks that it is important to publicly acknowledge the good work people are doing at the local level. In his view, more work should be done at the level of the national government to ensure accountability and publicize good work nationally. Loong Joon has been committed to sharing his approach and successes outside of his region with anyone who will listen. He thinks that people have to take legal actions by filing documentable complaints to report lack of compliance with laws and then follow up with persistence and dedication.

\section{Discussion}

Our study shows that Loong Joon is a passionate and effective implementation activist who is determined to ensure that young people do not take up smoking, and that all public places in Thailand become smoke-free. His activism is borne out of his frustration seeing that higher-level and local officials who are legally responsible for education and enforcement have not fulfilled their duties under the law. His simple philosophy is that people should respect the law, and officials should diligently fulfill their duties.

Asian Pacific Journal of Cancer Prevention, Vol 22 
Through his creative activist approach, Loong Joon analyzed the situation in his province and throughout Thailand, developed his own strategy to reduce youth smoking and achieve better enforcement of and compliance with smoke-free laws, and continuously monitored the impact of his work. Over many years, he developed a clear understanding of the legal system and Thailand's tobacco control laws that he was able to activate through his own human agency. Loong Joon concentrated his efforts primarily on improving conditions at schools and other government-owned public settings that the police have responsibility for protecting, and that the public sees as symbols of order and legal standards. Essentially, a decade before WHO issued their enforcement guidelines, Loong Joon took it upon himself to monitor compliance and make complaints reporting violations and requesting inspection visits, with the hope that authorities would respond swiftly and decisively.

Through his work, Loong Joon increased public awareness about the dangers of secondhand smoke. Through his shoe-leather activism, he has elevated the importance of creating and maintaining smoke-free places as a significant community value. Thus, his citizen's complaints have not simply been about reporting the lack of compliance with the law, but more fundamentally about emphasizing the basic social responsibility in communities to address the problems of youth smoking and SHS exposure that made the laws necessary. Loong Joon recognized that to realize the values embodied in the law, actions must be taken to increase understanding, ensure accountability, and build health promoting sociocultural norms.

\section{How Loong Joon assessed the problem}

Our study shows that the sociocultural context in Thailand has greatly shaped this implementation activist's perspective and informed how he goes about his work as a change agent. His method of implementation activism is similar to the iterative methodology of action research: questioning, observing, documenting conditions and his process, perturbing the system and predicting a result, monitoring his impact, revising his approach, and repeating the cycle (Stringer, 2007). Loong Joon intuitively realized that the main cause of lack of compliance was lax or nonexistent enforcement. He recognized that the sociocultural context and group dynamics in specific settings influenced whether officials enforced the law or not, and whether smokers complied with the law or not, as has been shown to be the case elsewhere (Moore et al., 2009; Irvin et al., 2015).

For many years, there was a lack of governmental commitment to provide financial and human resources dedicated to enforcement. In Loong Joon's view, this resulted in authorities shirking their responsibilities by not bothering to post and maintain required signage, and not bothering to conduct inspections and issue warnings or citations. Through experience, Loong Joon found that public education campaigns and warnings are necessary and important, but not sufficient to achieve compliance. His observations suggest that some government officials such as school administrators and police lacked knowledge about their obligations, but others lacked the will to enforce laws, most likely because they did not want to initiate potentially confrontational citation processes.

\section{Facilitators, barriers and challenges}

Loong Joon recognized that some aspects of Thai culture would be facilitators of his work, while other aspects would be barriers that present challenges. In terms of facilitators, Loong Joon knew that the law would be a major facilitator. Since Thailand, being a party to FCTC, had passed laws mandating $100 \%$ smoke-free public venues, Loong Joon knew when he started his work that there was a legal basis for him to file complaints about smoking in indoor public places, public transportation, and in many outdoor public spaces such as parks. The dissemination beginning in 2008 of specific notifications of the Nonsmokers' Health Protection Act gave Loong Joon a legal foundation for engaging in his work (Royal Thai Government, 2010). One critical facilitator of Loong Joon's work was that Thailand's tobacco control law required that when citizens file complaints with the police, the police were required to make inspection visits in response. Loong Joon recognized that he could potentially elicit a response from police and other enforcers because in Thailand, to a sufficient degree, the rule of law is respected. Conditions of relative personal safety throughout Thailand also facilitated Loong Joon's work.

Another major facilitator of Loong Joon's work was the nonsmoking public's dislike of smoking. This sociocultural resource provided Loong Joon with inspiration and gave him strength to engage in his work. When repeatedly notifying police about violations, Loong Joon knew that he had widespread public backing for his efforts to ensure that schools and other venues would contribute to creating healthier conditions for young generations and creating a society free of exposure to SHS. He framed his complaints as efforts to improve the environment for the public, especially for vulnerable populations like children, youth, and people suffering from respiratory illnesses. His framing was linked to Thai values about protecting vulnerable populations, and thus providing a strong justification for police to take action.

Additionally, public education campaigns were significant facilitators of his work. The "Toward 100\% Smoke-Free Thailand" campaign in 2008-11 was running when he initiated his strategy (Kungskulniti et al., 2018). A series of subsequent campaigns urged public compliance with smoking bans in various venues, and widespread tobacco control messaging helped to create conditions in which police, local government officials and responsible administrators became more aware of the issues of youth tobacco use and SHS exposure (World Health Organization, 2015; Pongutta et al., 2019).

In assessing barriers to implementation, Loong Joon recognized that Thai sociocultural patterns produced a context in which it was challenging to change some people's attitudes. Generations of Thais had accepted or tolerated smoking in public places. Many officials, the police and community members did not know about tobacco control laws. Officials tended to be lax in their responsibilities to enforce tobacco control laws, and 
smokers tended to ignore tobacco control laws unless they felt the law would be enforced. These patterns are part of wider Thai cultural patterns of permissiveness (mai pen rai), not wanting to inconvenience others (greng jai), tendency to avoid interpersonal confrontation and conflict, and law abidance based partly on fear of getting caught and being penalized (maa gat).

In engaging in his strategy, one substantial barrier to Loong Joon's success was that local officials and police were often not prepared to respond swiftly and decisively to his citizen's complaints. His work would have been substantially more effective if local governments had trained police and other inspectors to improve the frequency and quality of their inspections, and if they had worked to reduce public perceptions of official misconduct, corruption, or tobacco industry meddling (Peruga et al., 2017).

Loong Joon noted that he has experienced push back about his complaints. Police were not always willing to respond to his reports of administrators' outright defiance. It was not possible for Loong Joon to say definitively what caused the push back. Some of it may have been due to police officers being smokers themselves. Some may have been due to corruption or tobacco industry influence. Occasionally, persons in charge of government buildings felt slandered by Loong Joon's complaints and used their position of power or reputation in the community to counter his efforts. To deal with these problems, Loong Joon made efforts through outreach and filing complaints to raise awareness among police and officials about the importance of maintaining smoke-free areas. His persistent efforts over decades contributed to building his reputation as being credible.

Finally, it is important to note that to achieve his goals Loong Joon had the ability to use his own free time on weekends, and after he retired, even more of his free time. He also had sufficient resources to purchase a camera, pay for his own travel, and pay for developing his photos. Clearly, in Thailand and other LMICs some people who would aspire to be implementation activists do not have free time or sufficient recources to pay for these expenses.

\section{Elements of Loong Joon's creative approach that made him successful}

Loong Joon intuitively realized where he should strategically focus his efforts. He recognized that it is essential to create conditions at schools and other public places where everyone understands that smoking is prohibited and not tolerated. Creating these conditions likely resulted in smokers' peers telling them not to smoke, and smokers being weary of being cited if they violate the policy (Russette et al., 2014). Loong Joon observed that smokers were more likely to comply with total bans placing extensive restrictions on smoking, and that these restrictions had to be explicit in the form of clear accurate signage and followed up with regular enforcement (Borland et al., 2006; Zhou et al., 2016).

Loong Joon used his knowledge of Thailand's legal system and tobacco control laws as a basis for creating his simple yet systematic strategy of using his camera to document violations, writing notes, and submitting citizen's complaints to local police and officials. His photographs served as irrefutable evidence that police could not easily dismiss. Although Loong Joon developed his approach on his own, his strategy of documenting negligence and violations through photography and notifying officials is similar to the community-based approach developed in Yunnan known as Photovoice (Wang and Burris, 1997), and to an NGO's work in Kazakstan videotaping violators and submitting visual evidence to local officials (Open Society Institute, 2007). Like the Coalition for Tobacco Control Pakistan, Loong Joon has felt that it is necessary to conduct periodic observations in provinces throughout Thailand to identify and follow up on violations in public places.

Our findings demonstrate that it is possible for individual implementation activists to undertake this kind of work alone without the support of an NGO or a coalition as long as there are legal mechanisms for citizen's to file complaints. Loong Joon has independently engaged in using a kind of citizen's "soft power" - the power of notice - as a tool for compelling authorities to fulfill their enforcement duties. His fundamental revelation was that he must take personal responsibility as a citizen to hold officials accountable for their enforcement responsibilities under the law. His other revelation was that many Thai smokers will not follow the law unless they fear being fined, and few Thai nonsmokers and local administrators will dare to warn smokers that they are violating the law or local policies. In interacting with the police and administrators, he has worked toward denormalizing smoking in public settings by framing his notifications about lack of enforcement as a "teachable moment" (Shopik et al., 2012). Consistent with Thai sociocultural patterns, his non-confrontational approach has been diplomatic, avoiding smokers and seeking to work with police and local authorities rather than confronting smokers or shaming the police and local authorities.

In tobacco control work in LMICs, financial and human resources are often major impediments to making progress. Loong Joon has demonstrated that one healthy retired person can make a huge impact if they like to travel and take pictures, and have sufficient financial resources to pay for transportation, lodging, and developing film.

What activists in LMICs can learn about how to achieve implementation of laws

Every society has inherent obligations to denormalize smoking and vaping in indoor and outdoor spaces to prevent youth from consuming tobacco and nicotine, and to protect nonsmokers from exposures to harmful SHS and SHEE. These obligations begin with the passage of well-written laws. But the obligations do not end there. Countries are obliged to follow through to ensure that the public is informed of laws, and that the public complies with laws. Many LMICs continue to face difficulties going beyond passing laws. This includes countries like Thailand that are regarded as successful models of tobacco control.

WHO's MPOWER (Tobacco control actions of Monitor, Protect, Offer, Warn, Enforce, Raise Taxes) recommendations specifically outline activities in which enforcement activists can play important roles, including conducting systematic and consistent surveillance at 
the local level to monitor tobacco use and prevention policies, protecting people from tobacco smoke, and warning the public about the dangers of tobacco (World Health Organization, 2019a). While the MPOWER recommendations do not specifically talk about the role of implementation activisits, their role is evident in the intentions embodied in the FCTC and MPOWER.

Enforcement, while not the only approach to achieving compliance, has been shown to be an essential tool (Zhou et al., 2016). Loong Joon's reason for undertaking his efforts provides clear evidence of the importance of national, provincial/state and local governments for being committed to creating and maintaining smoke-free areas, and for establishing robust systems for monitoring the actions of enforcement authorities, and monitoring public compliance. Governments must designate and support specific enforcement officials, which may include public health inspectors, code enforcement officers, and police, and establish inspection procedures and processes for responding to citizen's complaints. Loong Joon's experience also shows that governments must also educate the public and inform smokers so that they have an opportunity to come into compliance (Montini and Bero, 2008).

Where enforcement is lacking and public compliance is low, Loong Joon's efforts offer important lessons for other tobacco control activists. A single committed implementation activist like Loong Joon can be an effective change agent. Implementation activists who see "the big picture" can identify where there is lack of coordination between local agencies, and they can leverage the legal system. Loong Joon's successes show that in LMICs, individual activists, even those who are not recognized stakeholders working in NGOs and coalitions, can ensure that laws and policies are implemented. Surveillance conducted by such implementation activists can contribute greatly to increasing public compliance.

The success of an implementation activist like Loong Joon depends on the existence of basic preconditions described above, namely well-written laws and policies, a defined enforcement process, basic public confidence in enforcement agencies, conditions of personal safety, and checks on tobacco industry interference. When these basic preconditions exist, those interested in becoming enforcement activists should be able to adapt Loong Joon's strategy to their own sociocultural context and replicate his successes.

Some observers have suggested that it is difficult to expect police officers to issue citations without national and local authorities first having made firm commitments to enforcing tobacco control laws (Open Society Institute, 2007). Loong Joon's experience provides an example of how in an LMIC, even when governments do not demonstrate firm commitments, it is still possible for implementation activists to intervene and use the citizen's complaint process to compel police to investigate violations and issue citations.

Research on strengthening enforcement efforts has described several approaches (World Health Organization, 2007a; World Health Organization, 2007b; Byron et al., 2019). Some have advocated "soft enforcement" approaches of phasing in enforcement through reminders before issuing fines (Bornhaeuser and Bloom, 2005; World Health Organization, 2007a; World Health Organization, 2007b). This approach makes it possible to educate the public about laws and policies before penalizing violators (World Health Organization, 2007b). However, experience has shown that when enforcement is delayed, local authorities can be prone to failing to implement the law, resulting in poor compliance (Montini and Bero, 2008). Loong Joon's experience suggests that in LMICs that face sociocultural barriers similar to those in Thailand, governments and the public may be better served by launching a media blitz about upcoming enforcement of laws and policies, and then following up immediately with strict and consistent enforcement, including issuing fines, to demonstrate the government's commitment to enforcement and compliance (Bornhaeuser and Bloom, 2005). Loong Joon's experience shows that in some cases enforcers may use their judgment to issue one formal warning before issuing fines so as to gain violators' appreciation and support (Bornhaeuser and Bloom, 2005). The success of this less stringent approach, however, depends on the capacity of enforcers to follow up diligently and re-inspect locations where they have issued one-time warnings.

Implementation activists can clearly work alone, but their efforts can be multiplied if legal capacity is increased and resources are made available (Open Society Institute, 2007). When the legal capacity is strengthened, implementation activists have a wider range of tactics they can pursue, such as filing a writ of mandamus notifying the court that a law exists that authorities are refusing to enforce (Montini and Bero, 2008). Some have noted that in the legislative arena, "champions" who are well-connected politicians sympathetic to the tobacco control cause can be influential (World Health Organization, 2007a; Chapman, 2011; Crosbie et al., 2011). Activists can benefit from relationships with champions (Montini and Bero, 2008). However, potential champions in elective office can be susceptible to tobacco industry influence. Loong Joon's approach bypasses the need to depend on an elected champion or other person with political influence. When governments or civil society groups run social media campaigns such as the successful smoke-free homes campaign that ran in Thailand in 2012, implementation activists can benefit from messaging broadcast throughout society that will support their work (Fotuhi et al., 2015).

Enforcement activists can submit suggestions about improving laws, and urge governments to establish provincial/state committees that promote individual local action. Thailand's 2017 Tobacco Product Control Act includes decentralization provisions establishing provincial tobacco committees (Royal Thai Government, 2017). These committees are starting to provide stakeholders with a means for coordination between activists, enforcers and employers. Such provincial committees can provide for opportunities for implementation activists to make their observations and views known. Implementation activists can also report local enforcement problems to those higher up, as was the case when Loong Joon sent a report to the Director General of the National Disease Control 
Department. Additionally, implementation activists can engage local and national reporters, as Loong Joon did, to inform them about serious problems that deserve coverage. In some cases, the forces that implementation activists come up against necessitate reaching out to the press to gain the public's attention (Goswami, 2006). Activists should also work with the press to inform the public about improvements and collaborative successes.

\section{Strengths and limitations of this study}

To our knowledge, this is the first study to identify a type of actor in the field of tobacco control we call an implementation activist. This is also the first study we are aware of to report extensively on an implementation activist's method of work and successes in an LMIC. Our analysis contributes to the limited body of evidence about the important role implementation activists can play in LMICs (Open Society Institute, 2007).

Our in-depth interviews with Loong Joon and the analytical approach we have taken, namely narrative analysis grounded in our familiarity with the Thai sociocultural context, are strengths of this study. Our approach draws from the rich anthropological literature based on life history interviews (Armendariz et al., 1997; Eibach, 2006; Betrisey, 2009; Van Der Sijpt, 2014; Wooyoung Kim et al., 2019).

A limitation of our study is that we were only able to document the approaches, methods and successes of one implementation activist. Our study does not draw from the experiences of activists conducting similar work in Thailand and/or in different LMICs. This is because we have not discovered anyone else in Thailand or in other LMICs who has worked at the scale and over so many years as Loong Joon has worked. However, in documenting Loong Joon's work, we have found similarities between his approach and those of other activists in LMICs described briefly in other reports. In LMICs, there are undoubtedly other implementation activists working locally who have experiences worthy of reporting. Fortunately, with regard to reporting on Loong Joon's specific case, there is a well-established precedent of reporting on individual cases when there is relatively little information about a topic in the literature, or when relatively few individuals engage in an activity, such as individuals who are leaders of social movements.

Although Thailand has banned the sale and use of e-cigarettes, we do not report on implementation activism focused on reducing youth use of e-cigarettes or SHEE exposure. This is because Loong Joon did not observe e-cigarette use in areas where he worked, and therefore he did not have cases to report to the police. Nevertheless, we recognize that activists in LMICs should be concerned about e-cigarette use and SHEE exposure.

Another limitation is that we could not independently verify the number of citizen's complaints Loong Joon filed, or independently confirm the percentage of complaints that were acted upon by the police. Since Loong Joon kept written records of nearly all of his work, we believe his self-reported data provide a reasonably reliable estimate of his impact.

As with any case study of an activist working in a specific sociocultural context, there are limits to how much the lessons drawn from this case can be generalized to conditions other activists face. Based on our assessment of common problems and conditions in LMICs, we believe that the necessary preconditions exist in many LMICs that are required to implement a locally-adapted version of Loong Joon's approach and potentially replicate his successes.

\section{Recommendations for policy and practice}

From our analysis of Loong Joon's statements about enforcement of smoke-free laws, we have identified the following recommendations that we think are applicable to conditions in many LMICs:

- Communities should prioritize making public areas $100 \%$ smoke-free and e-cigarette/vape-free with no exceptions for smoking areas, including at schools, religious settings, markets, sport facilities, public parks, national parks and beaches.

- Activists, civil society groups, public health officers and the police should work together to ensure that the public learns their responsibilities under the law to create and maintain smoke-free environments.

- Local public health officers and the police should be designated with the authority to enforce laws prohibiting smoking in public areas and for enforcing policies designating specific areas as smoke-free.

- Public health officers and the police should be educated about the specific language and requirements under smoke-free laws, and when available, about the citizen's complaint process, appropriate responses, and required actions.

- Activists and civil society groups should organize smoking cessation programs for higher-level officials, local public health officers and the police to gain their cooperation.

- Public health officers should work cooperatively with police to monitor public places regularly through unscheduled inspections, and warn or cite violators as appropriate.

- Higher-level officials, local public health officers and the police should be held accountable for achieving measurable goals, and reprimanded if they do not achieve them.

- Emphasis should be on achieving tangible measurable results e.g., posting signage, eliminating smoking in areas, reducing youth smoking rates, rather than solely conducting educational campaigns and contests.

- When local administrators, local public health officers and the police do not fulfill their duties to educate the public and enforce smoke-free laws and policies, activists and civil society groups should notify them of their responsibilities and try to open a dialogue about improving enforcement.

-Where appropriate, implementation activists and civil society groups may wish to alert local media about lax or non-existent enforcement.

- If necessary, implementation activists should report specific violations to higher-level officials who in turn should investigate cases to local administrators for action. The offices of provincial governors should follow up to

Asian Pacific Journal of Cancer Prevention, Vol 22 
ensure accountability.

Through Loong Joon's experience, we have identified the following recommendations for implementation activists to improve policy and practice to ensure enforcement of and compliance with the law. These recommendations are grounded in concepts in the conceptual framework for tobacco control and the action research cycle which is experimental and iterative (Unger et al., 2003; Stringer, 2007).

- Learn about the obligations one's country has agreed to in being a party to the FCTC.

- Learn about specific tobacco control laws and policies that should be enforced.

- Determine which governmental authorities are responsible for enforcement.

- Study and know the language of the specific laws and policies.

- Analyze the sociocultural context and administrative structures that are facilitators of and barriers to enforcement and compliance.

- Determine potential legal penalties for administrators not complying with laws and policies.

- Determine legal actions citizens can undertake such as filing citizen's complaints.

- Learn about legal procedures that citizens should follow to bring legal action against responsible authorities.

- Formulate a coherent approach based on a logical strategy and specific tactics.

- Work according to your own intuition and initiative, and at the same time coordinate with local groups when it is useful.

- Build on existing campaigns educating the public about youth tobacco, e-cigarette and heated tobacco product use, harms caused by SHS and SHEE exposure, and urge the public to comply with laws mandating smoke-free areas.

- Consider contacting reporters working for local or national press to inform them about the laws and policies, and educate them about problems with enforcement and compliance.

- Identify sites where required signage has not been posted clearly and accurately.

- Identify sites where administrators have failed to enforce laws and policies.

- Identify sites where smokers are not complying with relevant laws and policies.

- Document, ideally through photographs or videos, specific violations: lack of enforcement of and/or lack of compliance with existing laws and policies.

- Contact administrators who are responsible for enforcement and compliance at their site to use the case as a "teachable moment" to educate them about their duties and notify them about violations.

- Take legal actions such as filing complaints by following required legal procedures.

- Follow up with enforcers (e.g., inspectors and police) to hold them accountable.

- Keep records of each violation, administrator contacted, and legal action taken.

- Monitor what happens after taking legal action to measure the impact of the strategy.
- Re-analyze the sociocultural context and administrative structures to identify additional facilitators of and barriers to enforcement and compliance.

- Refine and rework the strategy to achieve greater impact.

- Send recommendations for improving enforcement and compliance to local and higher-level governmental authorities responsible for enforcement.

In conclusion, Loong Joon's work shows how one person's passion, understanding of the legal system, ingenuity, and dogged determination can produce substantial change for preventing youth from smoking and protecting the public from SHS and SHEE exposure. Loong Joon's sole motivation has been to protect members of society, particularly children, from taking up smoking and being harmed by SHS exposure. His efforts have contributed substantially to denormalizing tobacco use in public areas throughout Thailand.

Loong Joon successfully developed an effective method using existing legal mechanisms for filing citizen complaints to put sustained, pressure on bureaucratic systems. His approach bypasses common problems NGOs and coalitions face-lack of funding and lack of political support. His approach takes the provisions in the law and makes them meaningful. Loong Joon's work shows that success is possible if individual implementation activists point their camera at obvious negligence and report their findings. His leveraging of Thailand's public awareness campaigns with his legal actions furthered his hope that more efforts would be undertaken across the country to prevent young Thais from taking up tobacco and vaping, and for creating effective protections from SHS for millions of Thais.

Implementation activists see what is going on out in the world. So based on their observations and analyses they can also communicate their recommendations up to national-level officials. Loong Joon's experience shows that implementation activists can be champions in their own right, not depending on others with political power to be champions for them.

We hope this research will provide information about effective implementation activism. In LMICs, it will be important for those working in NGOs and academia to share this information with local activists since they rarely have access to research publications. The case we document provides a model for action through existing law. We believe activists in Thailand and other LMICs can benefit from adapting Loong Joon's approach to their own sociocultural context. It may also be possible for implementation activists in high-income countries to use some aspects of his approach.

Loong Joon's steadfast commitment to making an impact on Thai society through his persistent local efforts, particularly for the benefit of children and poor people, by filing one citizen's complaint after another, year after year, is what has made him particularly effective. This kind of dogged systematic local activism is where we see great potential for achieving improvements in implementation of and compliance with smoke-free laws, and for achieving meaningful change to further denormalize smoking and thereby improve people's health. 


\section{Author Contribution Statement}

The authors confirm contribution to the paper as follows: Conceptualization, N.C., N.K. and S.P.; data collection, N.C., N.K., V.P. and J.M.; methodology and analysis, S.H. and J.M.; interpretation of the data, N.C., N.K., S.H. and J.M.; supervision, N.C., N.K. and V.P.; writing-review and editing, N.C., N.K., S.H., J.M. V.P. and S.P. All authors reviewed the results and approved the final version of the manuscript.

\section{Acknowledgements}

The study was partially supported for publication by Faculty of Public Health, Mahidol University and Thailand Tobacco Control Research and Knowledge Management Center grant number 61-01-19. Dr. Mock's contribution was also supported by the California Tobacco-Related Disease Research Program through a Mackay CaliforniaPacific Rim Tobacco Policy Scholar Award grant number 28MT-0082.

The publishing cost was provided by WHO office in South-East Asia.

\section{References}

Ahuja N, Kathiresan J, Anand T, et al (2018). I have heard about it for the first time from you! Implementation of tobacco control law by police personnel in India. Public Health Action, 8, 194-201.

Armendariz A, Saunders JM, Poston SL, et al (1997). Exploring a life history of HIV disease and self-caring: Alfredo's story. $J$ Assoc Nurses AIDS Care, 8, 72-82.

Barnsley K, Walters EH, Wood-Baker R (2017). Political barriers to evidence-based tobacco control policy: Cronyism and cognitive dissonance, a Tasmanian case study. Evidence Policy, 13, 343-64.

Betrisey D (2009). Labor, social exclusion, and chronic muscular illness: the case of mid-impoverished sectors in a peripheral neighborhood in Madrid, Spain. Med Anthropol, 28, 65-80.

Borland R, Yong HH, Siahpush M, et al (2006). Support for and reported compliance with smoke-free restaurants and bars by smokers in four countries: findings from the International Tobacco Control (ITC) Four Country Survey. Tob Control, 15, 34-41.

Brandt AM (2007). The cigarette century the rise, fall, and deadly persistence of the product that defined America, New York, Basic Books.

Byron MJ, Cohen JE, Frattaroli S, et al (2019). Implementing smoke-free policies in low- and middle-income countries: A brief review and research agenda. Tob Induc Dis, 17, 60 .

Chang SH, Delgermaa V, Mungun-Ulzii K, et al (2009). Support for smoke-free policy among restaurant owners and managers in Ulaanbaatar, Mongolia. Tob Control, 18, 479-84.

Chapman S (2011). Why the tobacco industry fears plain packaging. Med J Aust, 195, 255.

Chotbenjamaporn P, Haruhansapong V, Jumriangrit P, et al (2017). Tobacco use among thai students: Results from the 2015 global youth tobacco survey. Indian J Public Health, 61, 40-6.

Crosbie E, Sebrie EM, Glantz SA (2011). Strong advocacy led to successful implementation of smokefree Mexico City. Tob Control, 20, 64-72.
Dang AK, Tran BX, Nguyen LH, et al (2018). Customers' perceptions of compliance with a tobacco control law in restaurants in Hanoi, Vietnam: A Cross-Sectional Study. Int J Environ Res Public Health, 15.

Douglas MR, Manion CA, Hall-Harper VD, et al (2015). Case studies from community coalitions: advancing local tobacco control policy in a preemptive state. Am J Prev Med, 48, 29-35.

Eibach U (2006). Life history, sin, and disease. Christ Bioeth, 12, 117-31.

Fong GT, Sansone G, Yan M, et al (2015). Evaluation of smoke-free policies in seven cities in China, 2007-2012. Tob Control, 24, 14-20.

Goswami H (2006). India: promoting tobacco via "research". Tob Control, 15, 274-5.

Gravely S, Driezen P, Ouimet J, et al (2019). Prevalence of awareness, ever-use and current use of nicotine vaping products (NVPs) among adult current smokers and ex-smokers in 14 countries with differing regulations on sales and marketing of NVPs: cross-sectional findings from the ITC Project. Addiction, 114, 1060-73.

Gvinianidze K, Bakhturidze G, Magradze G (2012). Study of implementation level of tobacco restriction policy in cafes and restaurants of Georgia. Georgian Med News, 206, 57-63.

Hovell MF, Hughes SC (2009). The behavioral ecology of secondhand smoke exposure: A pathway to complete tobacco control. Nicotine Tob Res, 11, 1254-64.

Irvin LH, Johnson L, Yamauchi J, et al (2019). Insights in public health: Formative Factors for a Statewide Tobacco Control Advocacy Infrastructure: Insights from Hawai'i. Hawaii $J$ Med Public Health, 78, 66-70.

Irvin VL, Hofstetter CR, Nichols JF, et al (2015). Compliance with smoke-free policies in Korean bars and restaurants in California: a descriptive analysis. Asian Pac J Cancer Prev, 16, 1083-9.

Janghorbani M, Taghdisi MH, Vingard E (2004). Public opinion on tobacco control policies in restaurants in Isfahan, Iran. Arch Iran Med, 7, 260-6.

Kashiwabara M, Arul R, Goswami H, et al (2011). Local governments and civil society lead breakthrough for tobacco control: lessons from Chandigarh and Chennai. Indian $J$ Public Health, 55, 234-9.

Kaur J, Jain DC (2011). Tobacco control policies in India: implementation and challenges. Indian J Public Health, 55, 220-7.

Kungskulniti N, Pitayarangsarit S, Hamann SL (2018). Stakeholder's assessment of the awareness and effectiveness of smoke-free law in Thailand. Int J Health Policy Manage, 7, 919-22.

Kyaing NN, Islam MA, Sinha DN, et al (2011). Social, economic and legal dimensions of tobacco and its control in South-East Asia region. Indian J Public Health, 55, 161-8.

Li X, Gao J, Zhang Z, et al (2013). Lessons from an evaluation of a provincial-level smoking control policy in Shanghai, China. PLoS One, 8, e74306.

Mendes FL, Szklo AS, Perez CA, et al (2017). Perceived enforcement of anti-smoking laws in bars and restaurants of three Brazilian cities: data from the ITC-Brazil survey. Cad Saude Publica, 33, e00140315.

Minh HV, Ngan TT, Mai VQ, et al (2016). Tobacco control policies in Vietnam: Review on MPOWER Implementation Progress and Challenges. Asian Pac J Cancer Prev, 17, 1-9.

Montini T, Bero LA (2008). Implementation of a workplace smoking ban in bars: the limits of local discretion. $B M C$ Public Health, 8, 402.

Moore RS, Lee JP, Martin SE, et al (2009). Correlates of persistent smoking in bars subject to smokefree workplace 
policy. Int J Environ Res Public Health, 6, 1341-57.

Nemakhavhani TR, Akinsola HA (2016). Survey of bar-lounges and restaurants regarding compliance with the current smoke-free regulation in Thulamela Municipality, South Africa. Afr J Prim Health Care Fam Med, 8, 1-6.

Nichter M (2003). Smoking: what does culture have to do with it?. Addiction, 98, 139-45.

Nyi Latt N, Saw YM, Myat Cho S, et al (2018). Tobacco Control Law awareness, enforcement, and compliance among high school students in Myanmar. Nagoya J Med Sci, 80, 379-89.

Owusu-Dabo E, Lewis S, McNeill A, et al (2011). Support for smoke-free policy, and awareness of tobacco health effects and use of smoking cessation therapy in a developing country. BMC Public Health, 11, 572.

Panda B, Rout A, Pati S, et al (2012). Tobacco control law enforcement and compliance in Odisha, India - Implications for Tobacco Control Policy and Practice. Asian Pac J Cancer Prev, 13, 4631-7.

Peruga A, Hayes LS, Aguilera X, et al (2017). Correlates of compliance with national comprehensive smoke-free laws. Tob Control, 2017.

Pongutta S, Suphanchaimat R, Patcharanarumol W, et al (2019). Lessons from the Thai Health Promotion Foundation. Bull World Health Organ, 97, 213-20.

Radwan GN, Emam AH, Maher KM, et al (2012). Public opinion on smoke-free policies among Egyptians. Int J Tuberc Lung Dis, 16, 1412-7.

Rashid A, Ab Manan A, Yahya N, et al (2014). The support for smoke free policy and how it is influenced by tolerance to smoking - experience of a developing country. PLoS One, 9.

Robertson L, Nyamurungi KN, Gravely S, et al (2018). Implementation of $100 \%$ smoke-free law in Uganda: a qualitative study exploring civil society's perspective. $B M C$ Public Health, 18, 927.

Russette HC, Harris KJ, Schuldberg D, et al (2014). Policy compliance of smokers on a tobacco-free university campus. $J$ Am Coll Health, 62, 110-6.

Schoj V, Alderete M, Ruiz E, et al (2010a). The impact of a $100 \%$ smoke-free law on the health of hospitality workers from the city of Neuquen, Argentina. Tob Control, 19, 134-7.

Schoj V, Sebrie EM, Pizarro ME, et al (2010b). Informing effective smokefree policies in Argentina: air quality monitoring study in 15 cities (2007-2009). Salud Publica Mex, 52, 157-67.

Shopik NA, Schultz AS, Nykiforuk CI, et al (2012). Impact of smoke-free hospital grounds policies: patient experiences and perceptions. Health Policy, 108, 93-9.

Siwaraksa P (2003). The Birth of the ThaiHealth Fund, Bangkok, Thai Health Promotion Foundation.

Stringer ET (2007). Action research, Los Angeles, California, Sage Publications.

Thai Health Promotion Foundation (2011). The Thai Health Professional Alliance Against Tobacco, Bangkok, Thai Health Promotion Foundation.

Thrasher JF, Nayeli Abad-Vivero E, Sebrie EM, et al (2013). Tobacco smoke exposure in public places and workplaces after smoke-free policy implementation: a longitudinal analysis of smoker cohorts in Mexico and Uruguay. Health Policy Plan, 28, 789-98.

Thrasher JF, Perez-Hernandez R, Swayampakala K, et al (2010). Policy support, norms, and secondhand smoke exposure before and after implementation of a comprehensive smoke-free law in Mexico city. Am J Public Health, 100, 1789-98.

Turner MM, Rimal RN, Lumby E, et al (2016). Compliance with tobacco control policies in India: an examination of facilitators and barriers. Int J Tubercul Lung Dis, 20, 411-6.
Uang R, Crosbie E, Glantz SA (2018). Tobacco control law implementation in a middle-income country: Transnational tobacco control network overcoming tobacco industry opposition in Colombia. Glob Public Health, 13, 1050-64.

Unger JB, Cruz T, Shakib S, et al (2003). Exploring the cultural context of tobacco use: a transdisciplinary framework. Nicotine Tob Res, 5, 101-17.

US Department of Health and Human Services (2006). Publications and Reports of the Surgeon General. In 'The Health Consequences of Involuntary Exposure to Tobacco Smoke: A Report of the Surgeon General', Eds Centers for Disease Control and Prevention (US), Office on Smoking and Health, Atlanta (GA),

Van Der Sijpt E (2014). "Passing children" and precarious pathways: on the contingency of reproductive life courses in Cameroon. Hum Fertil (Camb), 17, 192-6.

Vardavas CI, Dimitrakaki C, Schoretsaniti S, et al (2011). The role of the non-smoker in enforcing smoke-free laws. J Public Health Policy, 32, 46-59.

Vateesatokit P, Hughes B, Ritthphakdee B (2000). Thailand: winning battles, but the war's far from over. Tob Control, 9, 122-7.

Wang C, Burris MA (1997). Photovoice: concept, methodology, and use for participatory needs assessment. Health Educ Behav, 24, 369-87.

Wang L, Mamudu HM, Collins C, et al (2017). High prevalence of tobacco use and exposure to secondhand tobacco smoke among adolescents in low- and middle-income countries. Ann Transl Med, $\mathbf{5}$.

Wissarutwong C (2009). Tobacco Law, Bangkok, Sootpaisan Press.

Wooyoung Kim A, Kaiser B, Bosire E, et al (2019). Idioms of resilience among cancer patients in urban South Africa: An anthropological heuristic for the study of culture and resilience. Transcult Psychiatry, 56, 720-47.

World Health Organization (2019a). Tobacco Free Initiative MPOWER [Online]. Geneva. Available: https://www.who. int/tobacco/mpower/en/ [Accessed May 23 2020].

Xi B, Liang YJ, Liu YX, et al (2016). Tobacco use and secondhand smoke exposure in young adolescents aged 12-15 years: data from 68 low-income and middle-income countries. Lancet Global Health, 4, 795-805.

Ye X, Chen S, Yao Z, et al (2015). Smoking behaviors before and after implementation of a smoke-free legislation in Guangzhou, China. BMC Public Health, 15, 982.

Yousuf H, Hofstra M, Tijssen J, et al (2020). Estimated Worldwide Mortality Attributed to Secondhand Tobacco Smoke Exposure, 1990-2016. JAMA Netw Open, 3, e201177.

Zavala-Arciniega L, Reynales-Shigematsu LM, Lozano P, et al (2018). Patterns of awareness and use of electronic cigarettes in Mexico, a middle-income country that bans them: Results from a 2016 national survey. Prev Med, 116, 211-8.

Zhou L, Niu L, Jiang H, et al (2016). Facilitators and barriers of smokers' Compliance with Smoking Bans in Public Places: A Systematic Review of Quantitative and Qualitative Literature. Int J Environ Res Public Health, 13.

This work is licensed under a Creative Commons AttributionNon Commercial 4.0 International License. 